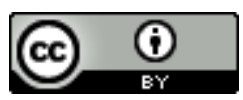

\title{
POLítICA DE COTAS E DEMOCRATIZAÇÃO dO ENSINO SUPERIOR: A VISÃO DOS IMPLEMENTADORES
}

\begin{tabular}{c}
\hline QUOTA POLICY AND DEMOCRATIZATION OF HIGHER EDUCATION: \\
THE VISION OF IMPLEMENTERS \\
POLÍTICA DE CUOTAS Y DEMOCRATIZACIÓN DE LA EDUCACIÓN SUPERIOR: \\
LA VISIÓN DE LOS IMPLEMENTADORES
\end{tabular}

\section{Andreliza Cristina de Souzai Mary Ângela Teixeira Brandalise}

\begin{abstract}
RESUMO: As políticas afirmativas vêm sendo alvo de discussões sob diferentes enfoques e perspectivas no contexto atual. Nesse sentido, este trabalho buscou analisar a política de cotas de uma Instituição de Ensino Superior pública estadual paranaense quanto à democratização do acesso e permanência no ensino superior na perspectiva de seus implementadores. Para tanto, as discussões estão apoiadas nas contribuições de Bourdieu (2010a; 2010b) sobre a teoria da violência simbólica e a reprodução das desigualdades dentro do sistema social e educacional. Foram ainda tratados os conceitos de democracia, igualdade e justiça social como elementos fundamentais para o estudo da política de cotas, com base nos estudos de Bobbio (2000), Bobbio, Matteucci e Pasquino (2008) e Crahay (2002). A pesquisa foi qualitativa e o instrumento escolhido para a coleta dos dados foi a entrevista semiestruturada. Para análise dos depoimentos foi utilizada a metodologia do Discurso do Sujeito Coletivo, de Lefèvre e Lefèvre (2005a; 2005b). À luz do referencial teórico e dos discursos coletivos oriundos dos depoimentos dos entrevistados percebeu-se que embora a tentativa de reprodução das desigualdades seja percebida e confirmada dentro da instituição, há a existência do movimento de superação das desigualdades sociais e educacionais pelo viés da educação, como afirma Cury $(1995 ; 2002)$. Os resultados da pesquisa permitem afirmar que a política de cotas da IES possibilita a democratização do acesso para uma parcela de estudantes antes excluídos do ensino superior. Nesse sentido, defende-se que trabalhos como este confirmam a importância do acompanhamento da implementação de políticas públicas como instrumento necessário para o exercício da democracia.
\end{abstract}

PALAVRAS-CHAVE: Democratização. Ensino superior. Política de cotas. Violência simbólica.

ABSTRACT:The affirmative policies have been the subject of discussions under different approaches and perspectives in the current context. In this sense, this work sought to analyze the quota policy of a State Higher Education Institution in the state of Paraná, regarding the democratization of access and permanence in higher education from the perspective of its implementers. To that end, the discussions are supported by the contributions of Bourdieu (2010a, 2010b) on the theory of symbolic violence and the reproduction of inequalities within the social and education system. The concepts of democracy, equality and social justice were also treated as fundamental elements for the study of quotas policy, based on Bobbio (2000), Bobbio, Matteucci and Pasquino (2008) and Crahay (2002). The research was qualitative and the instrument for the data collection was the semi-structured interview. For the analysis of the speechs, the methodology of the Collective Subject Discourse, by Lefèvre and Lefèvre (2005a; 2005b) was used. In the light of the theoretical reference and of the collective discourses derived from the interviewees' testimonies, it was noticed that although the attempt to reproduce inequalities is perceived and confirmed within the institution, there is the existence of a movement to overcome social and educational inequalities due to the education bias, As stated by Cury $(1995,2002)$. The

Submetido em: 20/06/2017 - Aceito em: 07/07/2017 - Publicado em: 08/08/2017.

\begin{tabular}{l|c|c|c|c|c|}
\hline C) Rev. Inter. Educ. Sup. & Campinas, SP & v.3 & n.3 & p.515-538 & set./dez. 2017 \\
\hline
\end{tabular}


results of the research allow us to affirm that the quota policy of the Institution of higher education makes it possible to democratize access to a portion of students previously excluded from higher education. In this sense, it is argued that works like this confirm the importance of monitoring the implementation of public policies as a necessary instrument for the exercise of democracy.

KEYWORDS: Democratization. Higher education. Quotas Policy. Symbolic violence.

RESUMEN: Las políticas afirmativas vienen siendo objeto de discusiones con diferentes enfoques y perspectivas en el contexto actual. Así, este trabajo buscó analizar la política de cuotas de una institución de educación superior pública estadual acerca de la democratización del acceso y permanencia en la educación superior, en la perspectiva de sus implementadores. Para eso, las discusiones están apoyadas en las contribuciones de Bourdieu (2010a; 2010b), sobre la teoría de la violencia simbólica y la reproducción de las desigualdades dentro del sistema social y educativo. Se abordaron los conceptos de democracia, igualdad y justicia social como elementos fundamentales para el estudio de la política de cuotas, con base en los estudios de Bobbio (2000), Bobbio, Matteucci y Pasquino (2008) y Crahay (2002). La investigación fue cualitativa y el instrumento elegido para la recolección de los datos fue la entrevista semiestructurada. Para el análisis se utilizó la metodología del Discurso del Sujeto Colectivo, de Lefèvre y Lefèvre (2005a; 2005b). A la luz del referencial teórico y de los discursos colectivos oriundos de los testimonios de los entrevistados se percibió que aunque el intento de reproducción de las desigualdades es percibido y confirmado dentro de la institución, existe la existencia del movimiento de superación de las desigualdades sociales y educativas através de la educación, como afirma Cury $(1995 ; 2002)$. Los resultados de la investigación permiten afirmar que la política de cuotas de la instituición posibilita la democratización del acceso a una parcela de estudiantes, antes excluidos de la educación superior. En ese sentido, se defiende que trabajos como éste confirman la importancia del acompañamiento de la implementación de políticas públicas como instrumento necesario para el ejercicio de la democracia.

PALABRAS CLAVE: Democratización. Educación superior. Política de cuotas. Violencia simbólica.

\section{INTRODUÇÃ̃o}

Historicamente o ensino superior público brasileiro é marcado por duas características: pela grande concorrência em seus concursos vestibulares e por a maioria de seu público ser pertencente ao topo da pirâmide social. A isso se pode atribuir duas razões. A primeira é que os alunos que possuem maiores recursos financeiros para se preparar para os exames vestibulares acabam por ocupar as vagas nas universidades públicas. A segunda pode ser atribuída ao fato de que o sistema de educação pública nacional é marcado pela precariedade. O aluno que usufrui do ensino público brasileiro, via de regra, faz parte da classe social menos privilegiada da sociedade e acaba sofrendo as consequências de um ensino deficitário. Assim, este aluno que frequenta a escola pública conta com professores com carga horária elevada, estrutura física e pedagógica de baixa qualidade, equipamentos, ambiente e condições de aprendizagem nem sempre favoráveis à aprendizagem. Frente a essa realidade ele se sente excluído, e, muitas vezes, um aluno com um sentimento de exclusão devido à sua classe social e baixa qualidade da educação formal que recebeu, acaba optando por uma desistência antecipada, antes que o próprio sistema educacional, condicionado pelos aspectos sociais, econômicos, políticos entre outros o, elimine.

\begin{tabular}{l|l|l|l|l|l} 
(C) Rev. Inter. Educ. Sup. & Campinas, SP & v.3 & n.3 & p.515-538 & set./dez. 2017 \\
\hline
\end{tabular}


Nas últimas duas décadas vêm ocorrendo um sensível crescimento no ingresso ao ensino superior por estudantes oriundos de escolas públicas e negros, historicamente excluídos do ensino superior, devido às políticas e programas educacionais de incentivo propostos pelo governo federal. Não se pode negar o efeito positivo desse aumento de estudantes, no entanto, é necessário levar em consideração as possibilidades de esse mesmo estudante conseguir finalizar o curso superior.

Muitos estudantes que não tinham condições de concorrer a uma vaga no ensino superior estão tendo a oportunidade de ingressar em universidades públicas em inúmeros casos graças a essas políticas, em particular as de ação afirmativa. A política de cotas é um exemplo de política de ação afirmativa e tem o objetivo de elevar o número de alunos negros e/ou oriundos de escola pública no ensino superior.

Entende-se que se faz necessária uma democratização do ensino, possibilitando o fortalecimento do acesso, mas, principalmente, a permanência do estudante nesse nível de ensino. Tais condições que são, muitas vezes, negadas pela realidade social, necessidades como alimentação, transporte, moradia e aproveitamento educacional, tornam-se questões que inviabilizam a permanência de estudantes beneficiados por tais políticas.

Nesse contexto, a presente investigação tem por objetivo analisar uma política de cotas para estudantes negros oriundos de escolas públicas e estudantes oriundos de escolas públicas de uma Instituição de Ensino Superior (IES) pública estadual paranaense quanto à democratização do acesso e permanência no ensino superior na perspectiva de seus implementadores. Esta investigação pretende contribuir com as discussões da área, possibilitando a compreensão do sistema de cotas por outro viés, decorrente da vivência dos sujeitos envolvidos (neste texto os implementadores) e da realidade da política de cotas implementada.

O texto está organizado em quatro seções. Na primeira nos apoiamos em Bourdieu (2010a; 2010b) para discutir sobre o papel da violência simbólica na exclusão e autoexclusão do sistema educacional. Nesta seção também abordamos os conceitos de igualdade e de justiça social para democratização do ensino superior. Na segunda seção trazemos os caminhos metodológicos da pesquisa e na seção seguinte a análise dos dados. Por fim, tecemos as considerações finais. Esperamos que o presente trabalho contribua para as discussões acerca da democratização do ensino superior enquanto possibilidade para se alcançar a igualdade real entre os cidadãos. 


\section{VIOLÊNCIA SIMBÓLICA, EXCLUSÃO E DEMOCRATIZAÇÃO DO ENSINO SUPERIOR}

O presente tema se mostra de elevada importância quando se fala em 'igualdade de oportunidades' e 'igualdade de resultados' no ensino superior, questão muito presente na atualidade (CRAHAY, 2002). Estas discussões atualmente colaboram com os debates mais amplos sobre como a ausência de direitos reais para determinadas classes sociais contribui para a perpetuação das desigualdades sociais.

Para melhor compreender o papel que a reprodução das desigualdades adquire frente ao sistema social e educacional, recorre-se à teoria da violência simbólica. Pierre Bourdieu pensou o sistema social como reprodutor das desigualdades existentes, dentro do loco das concepções de campo, capital e poder simbólico.

A educação pode ser tomada como um campo próprio, no qual existem lutas e embates específicos, sendo que está inserida na sociedade e sofre as implicações de grupos sociais determinados. A questão do acesso à educação superior é um dos embates que ocorrem dentro do campo da educação, sendo a democratização do acesso e a permanência discussões com grande relevância no momento atual.

Bourdieu afirma que ao longo da história a população tem acreditado no poder da educação para a mobilidade social, esperando que a ascensão do indivíduo (social e economicamente) se dê através da elevação do grau de estudo, ou seja,

É provável por um efeito de inércia cultural que continuamos tomando o sistema escolar como um fator de mobilidade social, segundo a ideologia da 'escola libertadora', quando ao contrário, tudo tende a mostrar que ele é um dos fatores mais eficazes de conservação social (BOURDIEU, 2010a, p. 41).

Para o autor, o sistema de ensino age para a perpetuação das diferenças entre classes, mostrando que os estudantes que obtém os melhores resultados fazem parte das classes que ocupam os mais altos lugares na pirâmide social e econômica.

Nessa concepção, o sistema educacional favorece a conservação social, oferecendo condições de ascensão a níveis mais elevados da sociedade àqueles que já são favorecidos. Em geral, são poucos os alunos pobres que almejam o ingresso no ensino superior, pois historicamente os estudos universitários fazem parte da vida daqueles que não têm a necessidade de trabalhar para garantir seu sustento e de sua família. Em uma sociedade em que a educação superior é tida como um privilégio de poucos, a grande maioria dos estudantes abre mão do 'sonho' do ingresso em uma instituição de ensino superior em virtude da tradição histórica de exclusão.

Fica clara, assim, a ideia de que as classes com maior capital econômico são as que possuem 
um grau também mais alto de capital cultural, e, logo, maior possibilidade para o acesso ao ensino superior. O sucesso destas, muitas vezes, não é atribuído aos fatores fundamentais como o de maior facilidade de acesso a bens culturais e ensino de qualidade, mas tido como 'natural' e, ousa-se dizer, lógico, pois filhos de pais ricos têm maior probabilidade de chegar a realizar um curso superior, ao passo que um aluno vindo de classes inferiores, muitas vezes, sequer consegue obter sucesso no ensino médio.

A habilidade que a escola possui de manter a ordem social lhe foi dada pelo poder simbólico que a educação possui. O poder simbólico é "[...] uma forma transformada, quer dizer, irreconhecível, transfigurada e legitimada, das outras formas de poder" (BOURDIEU, 2010b, p. 15). $\mathrm{O}$ autor diz que isso garante uma verdadeira transformação das relações de força e poder, de forma que a sociedade menos favorecida acaba por ignorar o reconhecimento desta violência. Assim, é possível manter as classes sociais divididas de acordo com os interesses dominantes sem que os sujeitos necessitem se envolver diretamente nos embates.

E através dessa violência simbólica os dominados continuam acreditando em sua situação como 'natural', não refletindo sobre os mecanismos que permeiam tal manutenção social e aceitando as diferenças de classes impostas como herança, algo que foi herdado por ele e que será deixada por ele. Esse status de 'herança' se atribui também ao capital cultural que cada família possui. O capital cultural pode ser definido como o conjunto 'habitus' que um grupo social possui, como, por exemplo, a valorização da leitura, familiarização com a arte etc. O capital cultural está diretamente ligado ao capital social que cada família possui.

O autor coloca que o capital cultural é, muitas vezes, o responsável pelo sucesso ou a exclusão que ocorrerá na vida escolar. As influências educativo-culturais que um indivíduo recebe ainda na infância interferem diretamente na vida educacional. Quando uma criança está familiarizada com objetos comuns à vida escolar e que favorecem o desenvolvimento intelectual, as atividades escolares se tornam naturais. Cada família é responsável por transmitir os valores embutidos nessa cultura, sendo que cada família transmite esses valores aos seus filhos, de maneira indireta.

Nesse panorama, pode-se perceber que o capital econômico age diretamente e pode ser o grande diferencial para a aquisição do capital cultural. Isso se explica pelo fato de que quanto maior o poder aquisitivo maior o acesso aos bens culturais, quanto maior for o grau de influências monetárias, mais o indivíduo se encontra próximo a fazer parte do sistema de ensino.

Bourdieu tece comentários quanto às diferenças de classe e as desigualdades de acesso: "vêse nas oportunidades de acesso ao ensino superior o resultado de uma seleção direta ou 
indireta que, ao longo da escolaridade, pesa com rigor desigual sobre os sujeitos das diferentes classes sociais" (BOURDIEU, 2010a, p. 41). Para Bourdieu a seleção pode ser direta, quando se trata de exames, ou indireta, quando o indivíduo se exclui antes mesmo do exame.

Para o sociólogo, fica claro na observação do sistema de ensino que muitos alunos se eliminam antes mesmo de serem eliminados. E quanto mais baixa for a classe na qual o estudante se insere, mais cedo ocorrerá esta exclusão. Para alguns, já cientes de sua situação de desvantagem frente à elite social e econômica, é mais fácil permanecer na situação onde se encontram, pois não há sentido em buscar possibilidades em um campo que ele não faz parte, e em seu ver, jamais fará. Essa concepção é muitas vezes passada aos indivíduos na escola, onde ele recebe a discriminação como subjetiva, natural, corriqueira e permanente.

Com efeito, para que sejam favorecidos os mais favorecidos e desfavorecidos os mais desfavorecidos, é necessário e suficiente que a escola ignore, no âmbito dos conteúdos do ensino que transmite, dos métodos e técnicas de transmissão e dos critérios de avaliação, as desigualdades culturais entre as crianças das diferentes classes sociais (BOURDIEU, 2010a, p. 53).

Essa forma de tratamento dada pelas escolas fortalece as desigualdades em todos os níveis da educação. Um aluno que é levado a acreditar que, em virtude de sua classe não tem chances no sistema educacional, dificilmente terá condições de transpor barreiras que são mais difíceis quando se eleva o nível educacional. E, as raras exceções, ou seja, os poucos indivíduos que conseguem transpor os obstáculos impostos a ele servem como legitimação da seleção escolar.

Quando alguns poucos alunos conseguem transpor as barreiras de classe e obtêm sucesso no sistema de ensino, acabam por dar crédito ao sistema excludente. Isso legitima o discurso de que 'quem se esforça obtém os melhores resultados' e de que 'o sucesso é uma questão de trabalho e dedicação’ (BOURDIEU, 2010a). O indivíduo que sofre com as discriminações e que consegue ascender seu capital cultural acaba sendo a legitimação que o sistema de ensino precisa para manter as diferenças entre classes.

Esta pode ser uma justificativa para a negação de grande parcela da sociedade em aceitar a utilização das políticas de cotas para o ingresso nas universidades, pois o sistema coloca a seu favor todos os fatos que permeiam o sistema de classes. Os detentores do capital econômico e cultural defendem veladamente a perpetuação das desigualdades, para que a chance de continuar a serem os únicos com acesso livre ao capital cultural continue sendo deles. 
Defende-se aqui a utilização das cotas nas universidades como uma forma de abrir o espaço acadêmico para os excluídos do sistema educacional ${ }^{2}$. Segundo Dias Sobrinho (2011, p. 121) "o direito social à educação de qualidade é um aspecto essencial e prioritário da construção da sociedade, de consolidação da identidade nacional, e um instrumento de inclusão socioeconômica. Por isso, assegurá-lo adequadamente é dever indeclinável do Estado".

Cury (1995, p. 28) mostra que essas modificações na estrutura da sociedade são possíveis, mesmo frente às análises sociológicas feitas por Bourdieu, pois, "se o capitalismo busca sua sistematização em termos de coerência e coesão, isso não quer dizer que exista como sistema acabado e fechado". O autor explica que a reprodução das desigualdades busca sua coesão nas relações de produção, no entanto, o contrário também acontece, ou seja, as relações podem ser superadas, pois "se as relações de produção se reproduzem e se ampliam, também as contradições se ampliam e se aprofundam, porque as relações de classe são contraditórias" (CURY, 1995, p. 28).

É nesse movimento que surgem as lutas de classe e a implementação de políticas públicas como a de cotas. Para Cury (1995, p. 42) "a reprodução é uma categoria que se dá no interior de um movimento contraditório cujo sentido, ainda que busque confirmar antagonismos existentes, também os empurra para sua superação. Essa reprodução, pois não se dá de modo mecânico ou meramente reflexo".

Nas palavras do teórico, "a educação é, então, uma atividade humana partícipe da totalidade da organização social” (CURY, 1995, p. 13). Entende-se, assim, que a educação acontece como um processo, que contempla as necessidades de o homem como ser histórico social, na dinâmica da dialética com a totalidade dos fatos.

Movimentos sociais de classe que lutam pela superação dessas relações vêm obtendo êxito em sua caminhada. A implantação de políticas afirmativas para inclusão de cidadãos antes excluídos do sistema de ensino mostra que a sociedade não sofre a violência simbólica passivamente. Para Cury (1995) ao mesmo tempo em que as relações são reafirmadas, as lutas de classe são acentuadas. Nesse sentido, é possível perceber que a violência simbólica sofrida pelas classes historicamente excluídas pode ser, e vem sendo, superada.

\footnotetext{
${ }^{2}$ Não se pode negar que a questão da qualidade da educação básica é um fator que merece ser discutido, uma vez que o atual sistema educacional brasileiro possui relevantes problemas. Conforme Machado e Magaldi (2016, p.277) "[...] entende-se que, para garantir que todos possam ter possibilidade de acesso ao ensino superior público, é necessário dar condições a todos de frequentar a educação básica e que o ensino público básico seja de qualidade, como sabemos que isso ainda não é uma realidade, apesar dos crescentes investimentos na melhoria da educação, acredita-se que o sistema de cotas é uma possibilidade de garantir a equidade/inclusão daqueles alunos oriundos de escolas públicas, que chegaram até o fim do ensino médio e que desejam cursar o ensino superior".
} 
As análises sociais realizadas por Bourdieu são muito válidas para explicar as relações de produção e reprodução, pois torna possível a compreensão de que o sistema educacional, com sua tradição meritocrática, exclui grande parcela de estudantes provindos de classes sociais mais baixas. Contudo, é necessário ir além para que seja possível compreender a totalidade da dinâmica das relações sociais. O próprio autor dizia que, ele, vindo de uma família humilde do interior, era uma afirmação e uma negação de sua teoria, uma vez que não ousou concorrer a cursos universitários de maior prestígio social, no entanto, obteve sucesso e visibilidade graças à educação de qualidade que recebeu.

A política de cotas se caracteriza como uma possibilidade de superação das desigualdades. $\mathrm{O}$ sistema social tenta limitar essa superação, reproduzindo desigualdades de outras formas, no entanto, esta política, mesmo fazendo parte de um sistema que sofre violência simbólica, contribui para a promoção de modificações na estrutura da pirâmide social e educacional, pois uma vez que proporciona a elevação dos níveis sociais, esse movimento abre possibilidade para que aquelas pessoas que vivem em condições socioeconômicas menos favoráveis também sejam elevadas socialmente.

A ascensão das classes sociais mais baixas mostra a importância que as políticas públicas têm para estudantes antes excluídos do cenário educacional brasileiro, e, nesse contexto, a política de cotas em especial (SOUZA, 2016). É nesse cenário que a política de cotas se destaca como uma possibilidade para a democratização do acesso ao ensino superior para aqueles historicamente (auto) excluídos.

A política de cotas se baseia no argumento de que a discriminação é a grande responsável pela sub-representação das minorias em posições de poder e prestígio e visa a criação de mecanismos para beneficiar esse público, destacando o fato de que, muitas vezes, estes alunos têm necessidades específicas para sua integração e permanência nos espaços universitários (OLIVEN, 2009; 2007; ALMEIDA, 2003).

Considerando que as políticas afirmativas buscam garantir uma igualdade real no tocante ao acesso ao ensino superior, ela pode ser considerada uma política de democratização (SOUZA, 2015). Remetendo aos fundamentos do termo, para Bobbio, Matteucci e Pasquino (2010) democracia pode ser compreendida na teoria clássica aristotélica como governo de todo o povo; na teoria medieval onde o poder deriva do povo e se transmite por delegação do superior para o inferior; e na teoria moderna originada em Maquiavel, concebe que existem somente duas formas de governo, a monarquia e a república, sendo a democracia mais uma forma de república. 
As discussões travadas sobre democracia política ao longo dos séculos envolveu, principalmente, um paralelo entre as duas doutrinas políticas dominantes: o liberalismo e o socialismo. Consideradas como doutrinas opostas no que se refere aos seus valores fundamentais, ambas são compatíveis com o conceito de democracia. Assim, "é perfeitamente correto falar de liberalismo democrático e de socialismo democrático" (BOBBIO; MATTEUCCI; PASQUINO, 2010, p. 326). Percebe-se então que a democracia se acomoda a doutrinas com conteúdos ideológicos diversos, pois "certamente nenhum regime histórico jamais observou inteiramente o ditado de todas estas regras; e por isso é lícito falar de regimes mais ou menos democráticos" (BOBBIO; MATTEUCCI; PASQUINO, 2010, p. 327).

Bobbio, Matteucci e Pasquino (2010) explicam que a democracia no Estado socialista representa um elemento integrante e necessário, mas não constitutivo. A democracia é uma das metas propostas pelo socialismo, isso porque sem a democracia não há uma profunda transformação da sociedade, no entanto, ela não é constitutiva porque a essência do socialismo é a revolução de classes e a modificação das relações econômicas e não apenas das relações políticas, da emancipação social no plano formal. Já no liberalismo a democracia é tida como censitária, elitista, uma extensão do mercado e, este sistema, reage com relação à democracia. Nesse sentido, no Estado liberal clássico não há a democracia plena, principalmente quando se observam os ideais da participação popular nas decisões que influenciam a sociedade. Essa limitação da democracia não é percebida pelas minorias, isso leva a uma democracia camuflada com preceitos de igualdade com o intuito de que as massas abram mão da verdadeira liberdade. Já no contexto educacional, Cury (2002) explica que o Estado é chamado a ser o provedor do direito à educação. Esse direito garante a igualdade de oportunidades, bem como intervém nas desigualdades oriundas pelos conflitos de distribuição de renda.

Frente aos múltiplos usos do termo, a política de cotas pode ser considerada uma política de democratização, já que facilita o acesso ao ensino superior para quem não tem chances iguais às dos demais para concorrer a esse nível de ensino. No entanto, a democratização do ensino superior é apenas um instrumento para se atingir a democracia plena, pois as conquistas formais são apenas instrumentos para a verdadeira socialização (DURIGUETTO, 2007).

No contexto deste trabalho entende-se que a democratização é um conceito amplo e que para ele se efetivar se faz necessário também conquistar a igualdade. Cury (2002) explica que na dialética entre o dever do Estado e o direito do cidadão no que se refere ao direito à igualdade e o direito à diferença em educação, esta não é uma relação simples. Para o autor: 
[...] a igualdade é o princípio tanto da não-discriminação quanto ela é o foco pelo qual homens lutaram para eliminar os privilégios de sangue, de etnia, de religião ou de crença. Ela ainda é o norte pelo qual as pessoas lutam para ir reduzindo as desigualdades e eliminando as diferenças discriminatórias (CURY, 2002, p. 255).

No entanto, a heterogeneidade entre as pessoas é mais visível que a igualdade, por isso aquela está sempre em detrimento desta. Para Bobbio (2000, p. 10) quando ao se falar em igualdade é necessário especificar: “a) igualdade entre quem?; e b) igualdade em quê?”. Nesse contexto, surge a igualdade de oportunidades e igualdade de resultados.

Para Crahay (2002, p. 53) o conceito de igualdade de oportunidades

[...] surge apenas a partir do momento em que a obrigatoriedade escolar produz o essencial dos seus efeitos e que todas ou quase todas as crianças são escolarizadas entre os 06 e os 12 anos. Parece então legítimo reclamar para todos o direito de adquirir uma formação da sua escolha, com a condição de que tenham as capacidades para tal, a origem social do individuo, o sexo, a nacionalidade, a sua origem étnica o regional, os rendimentos dos pais não podem constituir obstáculos.

Olhando por uma perspectiva mais crítica, a igualdade de resultados apresenta um terreno onde se pode presumir que as oportunidades não são iguais para todos os cidadãos. "Nessa interpretação do princípio, os resultados iguais deveriam ser projetados e construídos por meio da provisão de tratamentos desiguais" (WINCH; GINGELL, 2007, p. 134). Para Crahay (2002) a ideologia da igualdade de oportunidades é elitista, no entanto, quando vem acompanhada pela preocupação com a igualdade dos resultados, conduz às medidas de democratização do ensino. Este é um dos papeis das políticas afirmativas, democratizar as oportunidades ao ensino superior e promover a igualdade entre os cidadãos.

Nesse horizonte, faz-se necessário destacar que o conceito de igualdade está profundamente associado ao conceito de justiça. Em educação são muitas as áreas em que a questão da justiça social se torna relevante (WINCH; GINGELL, 2007).

\footnotetext{
$\mathrm{Na}$ perspectiva da justiça social e considerando as desigualdades econômicas e sociais existentes, deve-se considerar que os benefícios proporcionados por essa educação não podem permanecer restritos a apenas alguns grupos sociais que puderam frequentar boas escolas na educação básica e estão mais bem preparados para concorrer em exames de ingresso e para ter bom desempenho durante os cursos (PEIXOTO, 2011, p. 219).
}

Nesse contexto, a justiça social se consolida na participação popular efetiva no campo político. Nessa acepção, a justiça social é uma questão eminentemente política, e, por consequência, econômica. Isso leva a compreensão de que a política de cotas é também um fato político e econômico, sendo a justiça um meio de justificação para sua adoção, tendo 
como uma consequência a representação de classes historicamente excluídas e a redução das desigualdades educacionais e sociais.

\section{OS CAMINHOS DA PESQUISA}

Considerando os conceitos abordados e a temática das políticas afirmativas, a realização deste trabalho se assenta no campo da teoria crítica do conhecimento, que se configura como movimento de superação à reprodução das desigualdades. Destaca-se que, nesta pesquisa de cunho qualitativo, um olhar atento e sensível do pesquisador possibilitou extrair os significados atribuídos pelos sujeitos pesquisados, porque ela está calcada em uma densa partilha entre pessoas, fatos e locais que constituem o objeto da pesquisa.

A entrevista se mostrou um instrumento de coleta de dados bastante rico e significativo, uma vez que possibilitou conhecer a situação pesquisada pela ótica de seus partícipes e trouxe consigo a vantagem da riqueza do discurso proferido pelo sujeito pesquisado. A entrevista semiestruturada foi a utilizada para a realização deste trabalho. Esta forma de realizar a entrevista favoreceu um contato mais próximo com os entrevistados e possibilitou ao entrevistador explorar sua forma de pensar, seus saberes, representações, crenças e valores (LAVILLE; DIONNE, 1999). Este tipo de entrevista atendeu as necessidades da pesquisa, pois o depoimento de todos os sujeitos entrevistados está ligado à mesma ideia, o que facilitou a análise dos dados.

Foram realizadas sete entrevistas com os gestores da IES pesquisada que acompanharam a implementação da política de cotas na instituição. O roteiro de entrevistas foi elaborado segundo os objetivos da pesquisa e dos conceitos utilizados em sua elaboração. Cada uma teve duração média de vinte minutos, sendo que os entrevistados falaram livremente sobre todas as questões.

Os dados obtidos foram analisados à luz da metodologia do Discurso do Sujeito Coletivo (DSC). Essa proposta metodológica sinaliza a presença de um sujeito individual do discurso, mas também expressa uma referência coletiva, na medida em que esse 'eu' individual representa uma coletividade. O DSC consiste na análise do material verbal coletado, extraindo-se dos depoimentos as ideias-centrais (IC) e suas correspondentes expressões-chave $(\mathrm{ECH})$, para posterior composição de um ou vários discursos-síntese. Nessa metodologia, os vários discursos individuais obtidos são organizados na forma de um único pensamento coletivo sistematizado (LEFÈVRE; LEFÈVRE, 2005a).

A IC, também chamada categoria, pode ser entendida como a afirmação que permite exprimir o sentido essencial do conteúdo discursivo mencionado pelo indivíduo em seu depoimento, e também nos depoimentos dos diferentes indivíduos, que apresentem sentido semelhante ou

\begin{tabular}{l|l|l|l|l|l} 
(C) Rev. Inter. Educ. Sup. & Campinas, SP & v.3 & n.3 & p.515-538 & set./dez. 2017 \\
\hline
\end{tabular}


complementar (LEFÈVRE; LEFÈVRE; TEIXEIRA, 2000; LEFÈVRE; LEFÈVRE, 2005a; 2005b). Os DSCs são construídos com a essência das ECH, que são "transcrições literais de parte dos depoimentos" (LEFÈVRE; LEFÈVRE; TEIXEIRA, 2000, p. 18) e permitem que o pesquisador resgate a essência do conteúdo discursivo que, em geral, representa as respostas às questões de pesquisa.

Ao analisar os dados empregando essa metodologia a coletividade dos indivíduos foi considerada. Acredita-se que com a sua utilização, o processo de análise dos dados possibilitou a realização de novas reflexões acerca do objeto pesquisado, proporcionando o diálogo entre o dito e o vivido, o descrito e a realidade efetiva.

\section{DEMOCRATIZAÇÃO E REDUÇÃo dAS DESIGUALDADES}

A política de cotas na IES pesquisada foi implantada no ano de 2006, para ingresso dos estudantes cotistas no ano de 2007. A reserva foi de $10 \%$ das vagas de cada curso de graduação para candidatos oriundos de instituições públicas de ensino e de $5 \%$ para candidatos negros oriundos de instituições públicas de ensino. O prazo fixado para reserva de vagas foi definido em oito anos, sendo que a cada ano os limites mínimos de vagas seriam aumentados para cada cota, em 5\% a cada ano para estudantes oriundos de escolas públicas e $1 \%$ para estudantes negros oriundos de escolas públicas.

Os gestores universitários tiveram um importante papel na realização desta pesquisa. Considera-se fundamental envolver aqueles para quem a política foi pensada, o público-alvo, contudo, entende-se que não se pode esquecer o papel que os implementadores desempenharam na efetivação da política, pois é necessário atender aos interesses da politics para que uma policy ${ }^{3}$ seja realmente benéfica para todos os cidadãos.

Foram realizadas entrevistas com sete gestores envolvidos na implantação e acompanhamento da implementação política de cotas. O roteiro inicial da entrevista contava com onze questões, sendo que os depoimentos dos entrevistados foram agrupados, tratados e analisados conforme a metodologia do DSC. Neste artigo optou-se pela apresentação e discussão dos DSCs construídos em relação ao posicionamento dos gestores quanto à democratização do acesso ao ensino superior, promoção da justiça social e redução das desigualdades.

\footnotetext{
${ }^{3} \mathrm{O}$ termo 'polity’ faz referência às instituições políticas (partidos políticos), 'politics' designam os processos políticos (política no sentido de governabilidade) e, 'policy’ os conteúdos da política (programas e políticas públicas) (FREY, 2000).

(C) Rev. Inter. Educ. Sup. \begin{tabular}{l|l} 
Campinas, SP & v.3
\end{tabular}

n.3
p.515-538 set./dez. 2017
} 


\section{DSC sobre o posicionamento dos gestores a respeito da política de cotas quanto à democratização do acesso ao ensino superior ${ }^{4}$}

"Acho que esse é o grande objetivo da política de cotas: a democratização do acesso. Historicamente a universidade não foi criada pensando nas massas, historicamente ela foi criada pensando na condição de formação das elites, muito focada na questão do mérito. 'Só vai para universidade se você tiver mérito', se você provar esse mérito. A política de cotas veio justamente para democratizar o acesso. Então acredito que sim, ela favorece à pessoa que talvez não poderia ingressar entrar e isso é o papel da universidade pública. É um retorno que a universidade pública dá para a sociedade. O aluno de escola pública, muitas vezes, não tem aquele apoio tão significativo como tem os demais alunos, morando no centro da cidade. Eles não têm as condições de educação completa. Muitas das vezes os dois membros condutores da família trabalham fora e eles têm menos chance de melhorar a sua condição social. Se essas pessoas antes não podiam vir, não tinham acesso, o motivo era pela dificuldade de concorrência. Na medida em que nós demos a vantagem a elas em relação à concorrência elas passaram a entrar. Para as camadas populares, historicamente, o ingresso no ensino superior era um fator de ascensão social, mas hoje isso é muito relativo, você pode fazer um curso superior e esse curso não te levar a uma ascensão social. Mas também é muito claro, muitos estudos existem, de que quando uma pessoa da família chega a um curso superior ela contribui para a mudança do contexto de vários outros. Então se ele faz um curso superior ele não vai admitir que o filho não faça. Ele vai buscar condições melhores de formação para que esse filho chegue a um curso superior. Então quer dizer, é uma rede de coisas que você modifica. O principal mérito da política de cotas é buscar a democratização do acesso. E pelo que a gente tem observado ela tem cumprido esse papel.

Muitas pessoas, muitos acadêmicos que, tanto da escola pública quanto da cota de negros, não entrariam na universidade estão entrando. Esse é o objetivo: garantir que essas pessoas que numa outra condição não teriam acesso a universidade, possam ter acesso. E isso está acontecendo. Claro que não no número, no percentual do desejo que a gente tem. Por exemplo, hoje nossa instituição oferta cerca de 1700 vagas/ano. É pouco. É muito pouco se você for pensar quantos estudantes nós temos na fase dos 18 aos 24 anos. $\mathrm{O}$ que não quer dizer que a instituição não está tentando democratizar o ensino superior, porque em cursos como as licenciaturas, mesmo os cursos disputados, a gente faz um trabalho de criar condições para que as pessoas alcancem o título, o grau de ensino superior pela primeira vez na sua família. Mas acho que é preciso ampliar mais, o número de vagas no ensino superior".

Quanto à democratização do acesso, os gestores afirmam que a política de cotas atinge este objetivo e vem impulsionando a elevação dos índices de estudantes de escola pública e de estudantes negros no ensino superior desta instituição. Embora os gestores apontem que o número de estudantes que ingressam no ensino superior seja reduzido, já é mais expressivo que antes da implantação da política. Isto permite que a instituição tenha uma diversidade

${ }^{4}$ Os Discursos são compostos pela fala dos gestores entrevistados para a pesquisa. O lixo Discursivo, que são depoimentos que não estão em consonância com a questão ou expressões que não se repetem e/ou não compõem uma subcategoria (LEFÈVRE; LEFÈVRE, 2005b; LEFÈVRE; LEFÈVRE; CAVALCANTI, 2010), foram desconsiderados. Embora os depoimentos pareçam longos, estão compostos apenas com as Ideias Centrais que se repetiram nas entrevistas e representam o posicionamento dos gestores institucionais.

\begin{tabular}{l|l|l|l|l|l} 
(C) Rev. Inter. Educ. Sup. & Campinas, SP & v.3 & n.3 & p.515-538 & set./dez. 2017
\end{tabular}


maior de cor e tire o estigma da universidade exclusiva para as classes predominantemente brancas.

Aliada a isso, depreende-se do depoimento, a importância em destacar que além de políticas para acesso ao ensino superior é necessário que o sistema público de educação básica também seja democratizado. Machado e Magaldi (2016) explicam que uma educação básica de qualidade dará maiores condições de acesso ao ensino superior, no entanto, as desigualdades na formação inicial dos estudantes dificultam esse acesso. Para as autoras,

Como ainda estamos longe desse ideal, a discussão em torno da política de cotas raciais no Brasil surge como uma tentativa de dar condições àqueles que não estão em pé de igualdade com os demais, importante para a política e também para o amadurecimento das ideias presentes na sociedade" (MACHADO; MAGALDI, 2016, p. 282).

No depoimento é possível notar que os gestores consideram fundamental que as instituições de ensino público passem a considerar que seus estudantes farão parte de uma universidade futuramente. Nesse sentido, faz-se mister uma formação de qualidade para todos os alunos, já que estes sofrem com a violência simbólica, ou como diria Bourdieu (2010a), são herdeiros de uma concepção excludente de educação, que minimiza suas possibilidades de ingressar no ensino superior.

Sobre a questão da democratização do acesso, Dias Sobrinho (2011) fala sobre a relevância que as políticas afirmativas têm na sociedade, principalmente para as minorias. O autor revela que as classes mais pobres têm em média cinco anos de escolaridade, contra dez das classes mais ricas, "[...] mais de 14 milhões de analfabetos adultos, com mais de 25 anos, são um símbolo persistente do tradicional descuido do Estado e da sociedade, relativamente ao cumprimento do princípio da equidade em prol da diminuição da desigualdade por meio da educação" (DIAS SOBRINHO, 2011, p. 138). Nesse mesmo sentido, Peixoto (2011, p. 241) explica que "num sistema de ensino superior que tem apenas 200 anos, há, ainda, um longo caminho a percorrer [...]". Contudo, é necessário que haja um movimento de superação da desigualdade que produz a autoexclusão (BOURDIEU, 2010a). Nesse sentido, a política de cotas exerce uma função de extrema importância para a redução das desigualdades.

DSCs sobre o posicionamento dos gestores a respeito da política de cotas quanto à promoção da justiça social

I: "A política de cotas é uma desigualdade para quê? Para atingir uma igualdade. Ela é uma desigualdade na aparência, mas por quê? O que é a igualdade? É tratar igualmente os iguais e desigualmente os desiguais. Essa é a igualdade verdadeira. Então acho que essa política promove a justiça social sim. Ela faz com que corrija a 
desigualdade do momento que está existindo, e que se corrija essa distorção para que se possa caminhar, depois, todos juntos.

Muitos nem acreditavam na possibilidade de um dia chegar ao ensino superior. E hoje a gente percebe que há essa oportunidade. As vagas estão prontas para o aluno menos favorecidos. Mas, eu queria deixar bem claro, que isso não é o mais importante. O mais importante é perceber que algumas as escolas estão preocupadas com o ingresso desses alunos, estão fazendo avaliações mais justas, mostrando o interesse de que eles cheguem ao terceiro grau. Eu vejo isso porque a gente tem o projeto Universidade Aberta e nós fazemos visita às escolas com ensino médio e sente, muito interessante isso, sente que eles estão buscando chegar ao ensino superior. Mostrando assim a importância de ter um diploma do ensino superior. As ações afirmativas foram criadas, sempre, historicamente com esse objetivo, no mundo inteiro, para corrigir. E elas efetivamente corrigiram onde elas foram implantadas e em alguns momentos elas já foram até retiradas. Então saber o momento certo para que não se tire prematuramente, mas também não se prolongue muito, para que não faça o sentido inverso, de tensão, de gerar uma tensão social, ou uma discriminação, preconceitos é muito importante. É um assunto que tem que ser tratado com muito cuidado justamente para não estimular preconceitos $\mathrm{e}$ discriminação. Então por enquanto eu acho que esta instituição está no caminho certo, tem que continuar nesse rumo, vendo, cuidando sempre para isso, para que esse equilíbrio seja mantido".

II: “Acho que esse é um fator importante nessa promoção de justiça social. A gente só não pode imaginar, como algumas pensam, que ela deveria corrigir tudo na justiça social. Não. Ela cumpre o papel de correção dos problemas sociais, ela faz justiça social naquilo que ela pode, que é o acesso das pessoas ao ensino superior. Agora acho que ela não resolve o problema social amplo, porque para que a pessoa possa chegar a prestar um vestibular na universidade ela tem que ter terminado o ensino médio, e aí o problema é outro. É um problema que não vai ser cota que vai resolver. Porque a gente está começando pelo telhado e não pelo alicerce. Se a escola pública se fortalece, se a qualidade da escola pública melhora, se o maior número de pessoas que chega ao ensino superior é de escola pública, pelos méritos que a escola pública tem, pelas características que a escola tem, a própria sociedade vai percebendo o valor dessa escola. Eu acho que pode contribuir, porque na medida em que você tem mais pessoas da escola pública na universidade, e também percebe que a escola pública não é tão ruim como muita gente diz, na medida em que você tem mais estudantes negros na universidade, a convivência entre a diferença ela passa a ser menos rotulada, porque ela passa a ser natural, conviver com o diferente. Eu acho que pode contribuir. Acho que a política de cotas pode ser um passo. Mas também acho que cota vai ter um papel de melhorar a situação, de criar nas comunidades pessoas que vão ser exemplo, gente com ensino superior que vão ser exemplo para que outras pessoas da periferia, das classes populares se animem, se considerem gente do mesmo nível de qualquer outra para vir fazer vestibular. Isso eu vi quando eu fui numa escola de periferia em que uma menina tinha entrado em odontologia, e o sentimento que os alunos desse colégio de periferia, que consideravam que a instituição não era para eles, que eles nunca iam atingir, era uma coisa assim até emocionante de ver. Eles diziam 'Se ela, que era uma pessoa que estava aqui com a gente, que comia merenda com a gente, que pegava o ônibus com a gente, conseguiu entrar em odontologia, nós também conseguimos. Vamos ter que estudar o que ela estudou, mas nós também vamos conseguir'. Então acho que esse efeito que a política de cotas promove é fantástico. Ela joga lá em cima a autoestima dos alunos de colégios públicos de periferia que tem todo tipo de problema social, todo tipo de problema econômico e eles começam a perceber que eles também são gente, que eles também têm a capacidade que qualquer outro aluno

\begin{tabular}{l|c|c|c|c|c|} 
(C) Rev. Inter. Educ. Sup. & Campinas, SP & v.3 & n.3 & p.515-538 & set./dez. 2017 \\
\hline
\end{tabular}


tem. A gente tem que dimensionar nesse sentido: ela contribui para a superação da injustiça social, mas a gente tem que ter muita clareza da limitação dela. Ela é um grãozinho de areia. Ela é muito pouco. Eu particularmente acho que tem que melhorar, tem que insistir, mas tem que ter clareza que ela vai ter um resultado muito pequeno. Ainda assim, perto de zero pouca coisa já é muito. Nesse sentido vale a pena a cota mesmo".

Nestes discursos percebe-se que os gestores entendem que a política de cotas se apresenta como uma possibilidade para promoção da justiça social. São necessárias ações em diversos setores da sociedade, além da reforma do sistema de ensino básico público brasileiro, para que os cidadãos tenham condições de acesso a um ensino de qualidade e tenham condições de desencadear reflexões e lutar para solução de problemas sociais que atingem as classes mais desfavorecidas.

Para Dias Sobrinho (2011, p. 134), um dos principais aspectos a serem considerados para a democratização e promoção da justiça social na educação superior é a ampliação das matrículas na educação básica, no entanto o autor afirma que

[...] as importantes políticas de expansão do acesso só se efetivarão sob a condição de ter havido uma cobertura completa e com qualidade nos níveis educacionais precedentes, a começar pela pré-escola. Isso indica um obstáculo, cuja superação requer pesados investimentos públicos: é necessário empreender uma grande expansão da infraestrutura física das escolas de nível básico e, ao mesmo tempo, impulsionar vigorosamente a formação de mais bem preparados professores.

$\mathrm{Na}$ fala do autor fica claro que a questão do acesso ao ensino superior depende do investimento na educação básica, mas um importante ponto que merece ser destacado é a formação docente. Muitas vezes esta é uma questão que não ganha destaque quando se fala na educação enquanto instrumento que favorece a promoção da justiça social. Faz-se fundamental considerar que a qualidade da educação básica depende diretamente da formação de seus profissionais. Logicamente atrelada a outras questões de ordem mais ampla, como salários justos, condições de trabalho, infraestrutura, recursos didático-pedagógicos, entre outros, no entanto a formação docente configura-se como elemento chave para que a educação atue como promotora da justiça social.

Contudo, frente a esse cenário de precariedade, a política de cotas exerce um papel fundamental para o acesso ao ensino superior neste momento histórico. Assim como os gestores apontam no discurso, a elevação da qualidade do ensino básico é um pilar que necessita ser considerado para que haja uma efetiva democracia em educação. "Em outras palavras, qualidade em educação se vincula necessariamente com a justiça social, fundamento da democracia, e se constrói integrada, contínua e sistematicamente" (DIAS SOBRINHO, 2011, p. 134). Entende-se então que, embora as ações afirmativas contribuam para a redução das desigualdades, promover a qualidade do ensino básico é ponto fundamental para que a justiça social efetivamente exista.

\begin{tabular}{|l|l|l|l|l|l|} 
(C) Rev. Inter. Educ. Sup. & Campinas, SP & v.3 & n.3 & p.515-538 & set./dez. 2017 \\
\hline
\end{tabular}




\section{DSC sobre o posicionamento dos gestores a respeito da política de cotas quanto à redução das desigualdades}

"Na verdade, nós estamos falando que não existe igualdade, porque é hipocrisia da nossa parte dizer que "no Brasil não tem discriminação". Claro que tem. E a política afirmativa é justamente isso, afirmar que tem, além de fazer alguma coisa para resolver. Para mim igualdade é as pessoas serem bem tratadas, terem seus direitos respeitados independente de outras características mais específicas, seja de raça, seja de cor, seja de posição social. Eu acho que ela ajuda a preencher um vazio de cor que tem em muitos setores da sociedade. As cotas podem ajudar nesse processo de promoção da igualdade.

Elas não criam uma igualdade do nada, mas elas ajudam a fazer com que a igualdade avance ao fazer com que devagarinho vá desaparecendo esse vazio de outras cores, de outras etnias dentro das elites brasileiras. Quando eu penso elite não estou falando só do termo do dinheiro, mas na elite de cargo, na elite jurídica, na elite intelectual. Nesse sentido as cotas colaboram na promoção da igualdade.

E lógico, também tem aquele aspecto que tem em uma comunidade pobre: se você começar a ter as primeiras pessoas que são engenheiros, médicos, professores etc., essas pessoas exercem um papel duplo: elas vão ter uma renda melhor e vão melhorar a vida das suas famílias e também vão ter um papel simbólico para as crianças e adolescente que estão fazendo escola naquela comunidade. Acho que a política de cotas pode promover mais essa discussão, quer dizer, abre a discussão sobre as razões pelas quais determinados grupos podem estar tendo menos acesso a determinados bens. Mas não sei se é a partir dela ou por conta dela que essas coisas vão se resolver. Acho que são questões um pouco mais complicadas de se resolver. Coisas que envolvem mais o próprio conceito de cidadania, o próprio conceito de justiça. Não sei se ela chega a promover a igualdade entre os cidadãos, mas possibilita a todos os cidadãos que queiram, porque o importante é querer. Não adianta você ter uma política de cotas se as pessoas não estão motivadas a usufruir desse recurso e ir para a frente. É importante querer conquistar cada vez mais a sua capacitação. Ela favorece, sem dúvida nenhuma. Ainda mais quando você percebe dentro da análise de dados que a gente fez que há depoimentos dizendo da importância da política de cotas no âmbito familiar. A diferença que aconteceu com a família quando um membro pode chegar ao ensino superior. Ele gera um incentivo para a família. Eu acho que ela modifica bastante a sociedade, com certeza".

Os gestores afirmam que a política de cotas não tem o poder de promover a igualdade entre os cidadãos, mas tem o poder de ampliar os horizontes, apresentando possibilidades que antes eram praticamente impossíveis a determinados segmentos da sociedade. Um ponto a ser destacado é que os gestores afirmam que o ingresso de um estudante pertencente a uma realidade marcada pela escassez de recursos (financeiros, educacionais) permite que os demais sujeitos pertencentes à mesma realidade se percebam enquanto cidadãos, dotados de direitos e capazes de exercer sua cidadania. Assim como visto anteriormente, esse movimento dialético que a política de cotas impulsiona marca a tentativa da superação das desigualdades, pois uma chance desigual é dada na medida da desigualdade dos sujeitos e estes respondem com maior busca de seus direitos, diminuindo a distância entre o historicamente imposto e o socialmente possível. 
Dias Sobrinho (2011, p. 138) afirma que a educação é um direito de todos os homens, e nesse sentido, fala sobre a equidade em educação "por equidade, todo indivíduo deveria ter adequadas oportunidades de acesso à educação de qualidade, em todos os níveis". Isso demonstra que para que a igualdade se efetive são necessários muitos elementos, no entanto, a política de cotas se mostra como um fator que contribui para a efetiva promoção da igualdade.

Conforme vimos na primeira seção deste artigo, Bourdieu (2010b) explica que quando um estudante que não tem condições de ingressar no ensino superior consegue superar esta barreira, ele legitima o excludente sistema educacional, pois confirma que basta dedicação para merecer ingressar no ensino superior. No entanto, sabe-se que para haver democratização, além do acesso é necessário que haja permanência. Para Peixoto (2011) a permanência é um importante fator a ser considerado pelas IES, nas palavras do autor "[...] ela deve ser também objeto de políticas educacionais, com a formulação de medidas destinadas a proporcionar condições adequadas para que os alunos provenientes de famílias mais pobres possam frequentar o ensino superior e ter um bom desempenho nessa etapa de formação" (PEIXOTO, 2011, p. 221).

Retomando a discussão sobre democratização, igualdade e justiça social, remetemos novamente às ideias de Crahay (2002), pois estes são elementos fundantes para que haja a igualdade real entre as pessoas. Nesse sentido é possível afirmar que, mesmo que as políticas de ação afirmativa tenham limitações, a política de cotas contribui para a promoção da igualdade real entre os cidadãos e amplia o acesso ao ensino superior. Isso porque somente a luta permite uma mudança nas condições materiais "modificando e criando novas relações sociais" (ALMEIDA, 2006). Este é um primeiro passo para a superação da violência simbólica sofrida/exercida e para que relações mais justas sejam forjadas na sociedade.

Dos depoimentos analisados depreende-se que democratização, igualdade e justiça social são conceitos amplos e que muitas vezes a educação por si só não dá conta de garantir. Nas falas dos gestores fica clara a afirmação de que a educação age como instrumento de transformação das realidades desde os anos iniciais. No entanto, na realidade brasileira sabe-se que a democratização da educação no tocante ao acesso e sucesso é uma problemática que atinge todos os segmentos educacionais, e frente a esse fato a política de cotas configura-se como uma relevante possibilidade para transformação das realidades uma vez que amplia as chances de camadas historicamente excluídas ascenderem educacional e socialmente. isso mostra que mesmo de maneira parcial, as cotas agem como instrumento de democratização do ensino superior e vem, paulatinamente, inserindo as classes historicamente excluídas no panorama da educação superior brasileira.

\begin{tabular}{|l|l|l|l|l|l|}
\hline (c) Rev. Inter. Educ. Sup. & Campinas, SP & v.3 & n.3 & p.515-538 & set./dez. 2017 \\
\hline
\end{tabular}




\section{CONSIDERAÇÕES FINAIS}

Ao se tratar da educação como elemento que possibilita a transformação da realidade social das pessoas, é preciso considerar-se frente a um tema profundamente complexo, amplo e desafiador. Nesse sentido, as pesquisas em educação devem buscar o aperfeiçoamento do fenômeno educativo, suas instituições, sua estrutura, suas políticas e seus resultados, em busca de uma sociedade mais democrática, mais igualitária e mais justa.

Nesta perspectiva, o objetivo deste trabalho foi analisar a política de cotas implantada numa IES quanto à democratização do acesso e permanência no ensino superior para estudantes negros oriundos de escolas públicas e estudantes oriundos de escolas públicas. O presente trabalho resultou de reflexões sobre violência simbólica, democratização, igualdade e justiça social.

O processo de implantação da política de cotas na IES mostrou um longo e árduo trabalho para superação da resistência à implantação da política. Essa resistência se apresentou tanto por gestores institucionais quanto pela comunidade universitária e da comunidade externa. Neste processo percebe-se a tentativa da reprodução das desigualdades, discutida por Bourdieu (2010a; 2010b), quando o sociólogo diz que há a reprodução da ordem do sistema social no sistema educacional quando se defende a igualdade dos sujeitos e das oportunidades, mas de uma igualdade neoliberal, com bases no ideal meritocrático, cuja validade é dada pelos conceitos de justiça nela imbricados. Especialmente com relação às cotas raciais, que foi recusada por muitos envolvidos, e que demonstra como as discussões sobre racismo e preconceito, quando existem, são rasas na sociedade em geral (MOEHLECKE, 2002; FELICETTI; MOROSINI, 2009; BERGMANN, 1996; CERRI, 2008).

Contudo, neste quadro, a dialética da realidade se apresenta em seu movimento constante. Percebe-se claramente a contradição, através da tentativa de superação da reprodução social quando é observada a luta de muitos sujeitos a favor da implantação da política de cotas e a implantação efetiva desta. Ao passo que uma parte dos envolvidos luta pela manutenção social, outra parte luta pela superação das desigualdades (CRAHAY, 2002; CURY, 2002; CURY, 1995).

Frente a esse quadro, considera-se que as relações sociais interferem/contribuem no processo de implantação de uma política pública. Tal análise permite observar como o ir e vir de uma política se dá na realidade, uma vez que o contexto em que a política é implantada interfere diretamente em seu planejamento e produz novos significados (BRANDALISE, 2010; BRANDÃO, 2001; DRAIBE, 2001). Isso é notado quando as propostas foram ajustadas, de forma que atendesse às necessidades mais imediatas da polity, para que fosse sancionada, 
pois, é necessário que uma política pública atenda aos interesses dos envolvidos para que seja aprovada (DIAS SOBRINHO, 2003).

Assim sendo, a história dos sujeitos envolvidos, da comunidade afetada e da instituição em questão são elementos fundamentais que subsidiam as lutas e embates travados no campo. Estes são fatores que interferem diretamente não só na implantação de uma política, mas principalmente na implementação desta.

Nos depoimentos dos sujeitos da pesquisa foi possível perceber que houve uma grande resistência à política de cotas por uma parcela significativa da comunidade universitária. Entende-se que isso pode ter se dado em função de que as ações afirmativas buscam favorecer os sujeitos menos favorecidos para que estes tenham condições de exercer sua cidadania, usufruindo de seus direitos enquanto cidadão, desestabilizando assim a classe dominante de sua zona de conforto e segurança social.

O diálogo entre o referencial teórico escolhido e a coleta, organização e análise dos dados foi uma prática no processo de desenvolvimento desta pesquisa, caracterizando um movimento dialético de idas e vindas para a construção de um conhecimento sobre a política numa postura crítica.

O objetivo da política de cotas é beneficiar aqueles sujeitos que normalmente não têm condições de acesso ao ensino superior. Esta ação afirmativa é necessária, pois dificilmente serão ampliadas em tão curto espaço de tempo as vagas em instituições públicas. Segundo Dias Sobrinho (2011), por questões de justiça social e desenvolvimento, é dever do Estado prover as condições para que a educação se efetive como um bem social e, no cenário brasileiro a expansão, diversificação e alargamento do sistema de educação superior vem ocorrendo, no entanto, as instituições públicas não são o grande alvo dessa expansão.

Compreende-se como acompanhamento oferecer condições para que a política de cotas seja efetiva, ou seja, que proporcione aos estudantes condições de igualdade no ingresso e após ele. Nesse sentido, considera-se positivo que o estudante cotista seja tratado de maneira igualitária dentro da universidade, mas é importante lembrar que este não é igual aos demais. Ele ingressou por um sistema diferenciado, merece um acompanhamento diferenciado.

As informações desveladas no processo desta pesquisa possibilitam afirmar que de fato uma política tem 'vida': nasce, cresce, se desenvolve. Os dados empíricos constituem parte fundamental desta pesquisa, pois na dialética do cotidiano os sujeitos envolvidos não podem ser excluídos de um processo democrático. Nos discursos do sujeito coletivo fica evidente como a implementação da política vem ocorrendo institucionalmente. Na análise dos 
discursos foi possível perceber o grau de efetividade da política implementada, com suas potencialidades e fragilidades. As ideias-centrais demonstraram como a política de cotas foi implantada na instituição e oferecem elementos para desvelar a opinião dos gestores envolvidos com a política.

Pode-se afirmar que política de cotas analisada favorece a democratização do ensino superior, ainda que esta seja parcial, relativa. Mas, certamente a política de cotas tem favorecido a ampliação do acesso ao ensino superior. Contudo, é inevitável destacar que a violência simbólica sofrida pelos estudantes ao longo dos anos de educação básica é fator determinante para o ingresso ou exclusão do ensino superior.

É possível afirmar que ao mesmo tempo em que há a tentativa de reprodução das desigualdades sociais, há a tentativa da superação dessas relações desiguais. Quanto mais são acentuadas e elevadas as desigualdades, mais ocorre o movimento contrário, e a superação ganha espaço possibilitando transformações na realidade social, ainda que muito pequenas.

O movimento dialético das políticas públicas e da realidade é constante, atinge a todos, sem distinção. Basta estar no mundo para sofrer as influências, quanto mais em uma sociedade globalizada. Nesse movimento, todos precisam buscar uma posição, definir opinião e traçar suas lutas. As políticas afirmativas podem constituir-se num primeiro passo para a melhoria das condições de vida da população.

Esta pesquisa permitiu a todos observar que a política de cotas da instituição analisada vem possibilitando a ampliação do acesso ao ensino superior. Esta pesquisa não teve como pretensão decidir pelo sucesso ou fracasso da política de cotas. Ao contrário, buscou investigar as potencialidades e fragilidades observadas sob o ponto de vista dos gestores envolvidos na implantação e implementação.

Espera-se que esta pesquisa contribua para maiores discussões sobre as condições de ingresso e permanência de estudantes cotistas no ensino superior e para a criação de projetos institucionais que favoreçam a permanência desses estudantes, para o desenvolvimento de novas pesquisas acadêmicas sobre as políticas afirmativas e que desencadeie reflexões e discussões sobre a necessidade de se garantir a todo cidadão o direito à igualdade e o direito à diferença. 


\section{REFERÊNCIAS}

ALMEIDA, Maria de Lourdes Pinto. Políticas educacionais e pedagogia da exclusão: a escola em xeque no Brasil do século XXI. Revista Diálogo Educacional, Curitiba, v. 6, p. 33-34, 2006.

ALMEIDA, Mônica Andreia Oliveira. Políticas de Ação Afirmativa e Ensino Superior: a experiência do curso de graduação em Serviço Social da PUC-Rio. 2003. 131 p. Dissertação (Mestrado em Educação) - Pontifícia Universidade Católica do Rio de Janeiro, Rio de Janeiro, 2003.

BERGMANN, Barbara. In defense of affirmative action. New York: BasicBooks, 1996. $213 p$.

BOBBIO, Norberto. Igualdade e liberdade. Rio de Janeiro: Ediouro, 2000. 96p.

BOBBIO, Norberto; MATTEUCCI, Nicola; PASQUINO, Gianfranco. Dicionário de política. Brasília: Editora Universidade de Brasília, 2010. 2 v. 1318 p.

BOURDIEU, Pierre. A escola conservadora: as desigualdades frente à escola e à cultura. In: NOGUEIRA, Maria. Alice; CATANI, Afrânio. Escritos de educação. Petrópolis: Vozes, 2010a. p.40-64.

BOURDIEU, Pierre. O poder simbólico. Rio de Janeiro: Bertrand Brasil, 2010b. 314p.

BRANDALISE, M. Â. T. Autoavaliação de escolas: alinhavando sentidos, produzindo significados. Ponta Grossa: Editora UEPG, 2010.

BRANDÃO, Zaia. A dialética macro/micro na sociologia da educação. Cadernos de Pesquisa, São Paulo, n. 113, p. 153-165, jul. /2001. Disponível em:

<http://www.scielo.br/pdf/cp/n113/a08n113.pdf> acesso em: 08 jun. 2017.

CERRI, Luis Fernando. Notas críticas aos argumentos contra cotas para negros nas universidades públicas. In: FIÚZIA, Alexandre Felipe; CONCEIÇÃO, Gilmar Henrique Política, educação e cultura. Cascavel: Editora da Unioeste, 2008. p. 73-90.

CRAHAY, Marcel. Poderá a escola ser justa e eficaz? Da igualdade das oportunidades à igualdade dos conhecimentos. Lisboa: Instituto Piaget, 2002. 464p.

CURY, Carlos Roberto Jamil. Educação e contradição: elementos metodológicos para uma teoria crítica do fenômeno educativo. São Paulo: Cortez, 1995. 189p.

CURY, Carlos Roberto Jamil. Direito à educação: direito à igualdade, direito à diferença.

Cadernos de Pesquisa, São Paulo, n. 116, p. 245-262, julho 2002. Disponível em:

\begin{tabular}{l|c|c|c|c|c|} 
(C) Rev. Inter. Educ. Sup. & Campinas, SP & v.3 & n.3 & p.515-538 & set./dez. 2017
\end{tabular}


$<$ http://www.scielo.br/scielo.php?script=sci_arttext\&pid=S010015742002000200010\&lng=en\&nrm=iso >. Acesso em: 8 jun. 2017.

DIAS SOBRINHO, José. Educação superior: democratização, acesso e permanência com qualidade. In: DE PAULA, M. F. C.; LAMARRA, N. F. Reformas e democratização da educação superior no Brasil e na América Latina. Aparecida, SP: Ideia \& Letras, 2011. p. 121-152.

DRAIBE, Sônia Miriam. Avaliação de implementação: esboço de uma metodologia de trabalho em políticas públicas. In: BARREIRA, C. R. N.; CARVALHO, M. C. B. Tendências e perspectivas na avaliação de políticas e programas sociais. São Paulo: IEE/PUC-SP, 2001. p. 13-42.

DURIGUETTO, Maria Lúcia. Sociedade civil e democracia: um debate necessário. São Paulo: Cortez, 2007. 240p.

FELICETTI, Vera Lucia; MOROSINI, Marília Costa. Equidade e iniquidade no ensino superior: uma reflexão. Ensaio: avaliação e políticas públicas em educação. Rio de Janeiro, v. 17, n. 62, p. 9-24, Mar. 2009. Disponível em:

$<$ http://www.scielo.br/scielo.php?script=sci_arttext\&pid=S0104$40362009000100002 \& \operatorname{lng}=e n \& n r m=i$ iso $>$. Acesso em: 8 jun. 2017.

FREY, K. Políticas públicas: um debate conceitual e reflexões referentes à prática da análise de políticas públicas no Brasil. Planejamento e Políticas Públicas, Rio de Janeiro, n. 21, p. 211-259, jun 2000. Disponível em: 〈http://www.ufpa.br/epdir/images/docs/paper21.pdf>. Acesso em: 8 jun. 2017.

LAVILLE, Christian; DIONNE, Jean. A construção do saber: manual de metodologia da pesquisa em ciências humanas. Porto Alegre: Artmed, 1999. 342p.

LEFÈVRE, Fernando; LEFÈVRE, Ana. Maria Cavalcanti. Depoimentos e discursos: uma proposta de análise em pesquisa social. Brasília: Liber Livro, 2005a. 97p.

LEFÈVRE, Fernando; LEFÈVRE, Ana Maria Cavalcanti. O discurso do sujeito coletivo: um novo enfoque em pesquisa qualitativa (desdobramentos). Caxias do Sul: Educs, 2005b. $256 \mathrm{p}$.

LEFÈVRE, Fernando; LEFÈVRE, Ana Maria Cavalcanti; TEIXEIRA, Jorge Juarez Vieira. O discurso do sujeito coletivo: uma nova abordagem metodológica em pesquisa qualitativa. Caxias do Sul: EDUCS, 2000. 138p.

MACHADO, Carla Silva; MAGALDI, Caroline Alves. Sistema de cotas, trajetórias educacionais e assistência estudantil: por uma educação inclusiva. Revista Eletrônica de Educação, São Carlos, 10, n. 2, Ago. 2016. 273-285. 
MOEHLECKE, Sabrina. Ação afirmativa: história e debates no Brasil. Cadernos de

Pesquisa, n. 117, p. 197-217, novembro 2002. Disponível em:

$<$ http://www.scielo.br/scielo.php?script=sci_arttext\&pid=S0100-

15742002000300011\&lng=en\&nrm=iso>. Acesso em: 8 jun. 2017.

OLIVEN, Arabela Campos. Ações afirmativas nas universidades brasileiras: uma questão política, um desafio pedagógico. In: FRANCO, M. E. D. P.; KRAHE, E. D. Pedagogia Universitária e Áreas de Conhecimento. Porto Alegre: EdiPucrs, 2007. p. 151-160.

OLIVEN, Arabela Campos. Ações afirmativas na Universidade Federal do Rio Grande do Sul e o seu significado simbólico. Educação, Santa Maria, v. 34, n. 1, p. 65-76, jan/abr 2009. Disponível em: <https://periodicos.ufsm.br/reveducacao/article/view/1589/885>. Acesso em: 8 jun. 2017.

PEIXOTO, Maria do Carmo Lacerda. Políticas para a democratização do acesso e a inclusão social na educação superior do Brasil. In: DE PAULA, M. F. C.; LAMARRA, N. F. Reformas e democratização da educação superior no Brasil e na América Latina. Aparecida, SP: Ideia \& Letras, 2011. p.217-244.

SOUZA, Andreliza Cristina de; BRANDALISE, Mary Ângela Teixeira. Democratização, justiça social e igualdade na avaliação de uma política afirmativa: com a palavra, os estudantes. Ensaio: aval.pol.públ.Educ., Rio de Janeiro, v. 23, n. 86, p. 181-212, fev. 2015.

SOUZA, Andreliza Cristina de; BRANDALISE, Mary Ângela Teixeira. Avaliação da política de cotas da UEPG: desvelando o direito à igualdade e à diferença. Avaliação (Campinas), Sorocaba, v. 21, n. 2, p. 415-438, July 2016.

WINCH, Christopher; GINGELL, John. Dicionário de filosofia da educação. São Paulo: Contexto, 2007. 256p.

\section{${ }^{\mathrm{i}}$ Sobre as autoras}

\section{Andreliza Cristina de Souza}

E-mail: andrelizacsouza@ gmail.com / ORCID: http://orcid.org/0000-0002-4860-7608

Universidade Federal de São Carlos - Brasil

Doutoranda em Educação pela Universidade Federal de São Carlos [UFSCar]

Mary Ângela Teixeira Brandalise

E-mail: marybrandalise@ uol.com.br / ORCID: http://orcid.org/0000-0003-3674-5314

Universidade Estadual de Ponta Grossa - Brasil

Doutorado em Educação pela Pontifícia Universidade Católica de São Paulo [PUC-SP] 
